\title{
PHYSIQUE AND FAMILY ENVIRONMENT IN GIRLS ATTENDING A WELSH COLLEGE
}

\author{
BY \\ T. C. DANN, M.A., M.D., D.Obst.R.C.O.G. \\ Medical Officer, University College, Swansea \\ AND \\ D. F. ROBERTS, M.A., D.Phil. \\ Reader in Human Genetics, University of Newcastle upon Tyne
}

It is a curious fact of the biology of the modern population of Britain that, whereas there is little association between menarcheal age and social class (Douglas, 1964; Nisbet and Illesley, 1963), there remain by contrast clear differences in height and weight between children of different socioeconomic groups. These physique differences persist into adulthood (Clements and Pickett, 1957; Thomson, 1959). This contrast between menarcheal age and body size is the more surprising since both share in the well-established secular trend towards earlier attainment of the former and increase of the latter (Tanner, 1962, 1965).

A recent and continuing study of girls in a Welsh college (Roberts and Dann, 1967), the object of which was to assess the relative contributions of particular factors of the environment to variation in menarcheal age, showed, as in other recent studies in Britain, no detectable effect of socio-economic status on menarcheal age. Possible explanations proposed were that the Registrar General's socioeconomic categories are no longer meaningful in terms of expenditure on food, standards of housing, etc., factors which influence biological development; or that socio-economic differences have been eliminated as effective influences of biological development during the growth of the subjects. In the latter respect the sample was unusually uniform; the years of birth (1939-1946) and early life of the subjects covered a period of economic stringency and nutritional uniformity, and indeed it was this relative homogeneity that prompted the initial analysis. In the light of this homogeneity, it appeared of interest to analyse further the data on physique collected from these same girls to ascertain whether socioeconomic differences could be detected. The results

Reprints can be obtained from the Laboratory of Human Genetics, University of Newcastle upon Tyne, 19 Claremont Place, Newcastle
upon Tyne, NE2 4AA. are presented here. They relate to a sample of 655 girls, born in 1939 and later, admitted to the University College of Swansea during the period 1959 to 1964 , at which date they were between the ages of 18 and 21 . The sample included no girls born outside Britain and no girls who were coloured.

All the subjects were measured in their first halfyear of residence by the same observer, using the same instruments and giving the same instructions to each, e.g., for stature, to stand as upright as possible and to look horizontally before her; final adjustment of the head into the Frankfurt plane was completed by touch. Thus the variation included no inter-observer or inter-instrument error, and there is no reason to suppose any consistent trend in intra-observer or posing error over the years in which the work was undertaken. All measuring was done between the hours of 10 a.m. and 4 p.m. and the same numbers of girls were being measured in the morning and afternoon sessions at the end as at the beginning of the survey; thus, while diurnal variation may contribute slightly to the variance in stature, no consistent trend is likely.

\section{Results}

The following independent variables were considered for each girl:

$X_{1}$ year of birth less 1900 ,

$\mathrm{X}_{2}$ family size as measured by the number of siblings she has,

$X_{3}$ the numerical position of the girl in the family, $X_{4}$ the father's occupation described numerically as in the Registrar General's classification.

The following dependent variables were considered separately:

$Y_{B}$ the ponderal index measured as $\frac{\text { stature }}{\sqrt[3]{\text { weight }}}$ 
TABLE I

MEANS AND STANDARD DEVIATIONS

\begin{tabular}{|c|c|c|c|c|c|c|c|c|c|c|c|c|c|}
\hline \multirow{2}{*}{$\begin{array}{c}\begin{array}{c}\text { Social } \\
\text { Class }\end{array} \\
1 \\
2 \\
3 \\
4 \\
5\end{array}$} & \multirow{2}{*}{$\begin{array}{c}\begin{array}{c}\text { No. in } \\
\text { Sample }\end{array} \\
155 \\
142 \\
249 \\
83 \\
26\end{array}$} & \multicolumn{2}{|c|}{$\underset{\text { Mean }}{\text { Xear }_{1}} \underset{\text { Birth }}{\text { S.D. }}$} & \multicolumn{2}{|c|}{$\underset{\text { Mean }}{\text { Family Size }} \underset{\text { S.D. }}{\mathbf{X}_{\mathbf{2}}}$} & \multicolumn{2}{|c|}{$\begin{array}{c}\text { Position in Family } \\
\text { Mean }\end{array}$} & \multicolumn{2}{|c|}{$\underset{\text { Mean }}{\mathbf{Y}_{\text {Stature }}}$ S.D. } & \multicolumn{2}{|c|}{$\underset{\text { Mean }}{\text { Weight }_{\text {S.D. }}^{Y_{7}}}$} & \multicolumn{2}{|c|}{$\begin{array}{l}\mathbf{Y}_{\mathbf{5}} \\
\text { Ponderal Index } \\
\text { Mean }\end{array}$} \\
\hline & & $\begin{array}{l}43 \cdot 59 \\
43 \cdot 20 \\
43 \cdot 27 \\
42 \cdot 94 \\
42 \cdot 27\end{array}$ & $\begin{array}{l}1.91 \\
1.97 \\
1.80 \\
2.08 \\
1.59\end{array}$ & $\begin{array}{l}1 \cdot 18 \\
1 \cdot 25 \\
1 \cdot 19 \\
1 \cdot 36 \\
1 \cdot 12\end{array}$ & $\begin{array}{l}1.00 \\
1.14 \\
1.09 \\
1.66 \\
1.58\end{array}$ & $\begin{array}{l}1 \cdot 50 \\
1 \cdot 51 \\
1 \cdot 58 \\
1 \cdot 70 \\
1 \cdot 42\end{array}$ & $\begin{array}{l}0.76 \\
0.90 \\
0.93 \\
1.14 \\
0.90\end{array}$ & $\begin{array}{l}64 \cdot 08 \\
64 \cdot 21 \\
63.92 \\
63.49 \\
63.00\end{array}$ & $\begin{array}{l}2 \cdot 13 \\
2 \cdot 23 \\
2 \cdot 37 \\
2 \cdot 46 \\
2 \cdot 57\end{array}$ & $\begin{array}{l}128 \cdot 10 \\
127 \cdot 33 \\
127 \cdot 35 \\
129 \cdot 39 \\
124 \cdot 15\end{array}$ & $\begin{array}{l}16 \cdot 89 \\
14 \cdot 62 \\
18 \cdot 16 \\
20 \cdot 22 \\
19 \cdot 45\end{array}$ & $\begin{array}{l}12.75 \\
12.79 \\
12.75 \\
12.60 \\
12.68\end{array}$ & $\begin{array}{l}0.47 \\
0.47 \\
0.53 \\
0.59 \\
0.52\end{array}$ \\
\hline
\end{tabular}

TABLE II

MULTIPLE REGRESSION ANALYSIS-TOTAL SAMPLE

\begin{tabular}{|c|c|c|c|c|}
\hline \multirow{2}{*}{ Regression Equations } & \multicolumn{4}{|c|}{ Standard Errors of Regression Coefficients } \\
\hline & $\mathbf{X}_{\mathbf{1}}$ & $\mathbf{X}_{\mathbf{2}}$ & $\mathbf{X}$ & $\mathbf{X}_{\mathbf{4}}$ \\
\hline 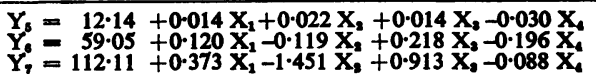 & $\begin{array}{l}0 \cdot 011 \\
0 \cdot 048 \\
0 \cdot 362\end{array}$ & $\begin{array}{l}0 \cdot 023 \\
0 \cdot 104 \\
0 \cdot 793\end{array}$ & $\begin{array}{l}0 \cdot 030 \\
0 \cdot 135 \\
1 \cdot 030\end{array}$ & $\begin{array}{l}0.018 \\
0.082 \\
0.625\end{array}$ \\
\hline
\end{tabular}

which gives a measure of the linearity of physique and which ranged from 10.68 for the plumpest to 14.30 for the most slender,

$Y_{6}$ height in inches, measured to the nearest half inch, which ranged from 58 to $72 \frac{1}{2}$ in.

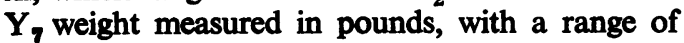
86 to $207 \mathrm{lb}$. The means and standard deviations for each variable by social class $\left(X_{4}\right)$ are given in Table $I$.

Of the zero order correlation coefficients between any of the independent and any of the dependent variables, only those between stature and year of birth, and between stature and social class $(+0.114$ and -0.103 respectively), were significant. A multiple regression was undertaken of each dependent variable on the four independent. The results are shown in Table II. The regression equations of ponderal index and of weight on the four variables were not significant, neither were any of the individual regression coefficients. But the regression of height on the four variables was significant and, of the individual regression coefficients, those on year of birth and social class attained significance at the 2 per cent. level. There was no detectable effect of family size or birth order. Although these effects are detectable, their importance should not be exaggerated, for they account for only a small proportion of the total variation. For ponderal index, weight, and height respectively, the multiple correlation coefficient, $R$, with all the independent variables, in the total sample is $0.089,0.089$, and 0.128 ; these values imply that some 99 per cent. of the total variation in each remains to be explained after the variables here considered have been taken into account.

Since it may not be valid to treat the socio-economic classification as a numerical variable, this was examined further. The analysis was repeated in the total sample ignoring social class and then within the social classes. The regression coefficientso are given in Table III; they differ little from those_in Table II. The regressions for ponderal index and $\bar{z}$ weight, both overall and within classes, were not significant, nor were any of the individual regression coefficients. On the other hand, the regressions foro height were again significant and, of the regression. coefficients on individual variables, that on (year of birth) was highly so. This analysis allowed

TABLE III

COVARIANCE ANALYSIS REGRESSION COEFFICIENTS

\begin{tabular}{|c|c|c|c|c|c|c|}
\hline \multicolumn{4}{|c|}{ Overall } & \multicolumn{3}{|c|}{ Within Classes } \\
\hline & $\mathbf{X}_{1}$ & $\mathbf{X}_{\mathbf{8}}$ & $\mathbf{X}_{\mathbf{3}}$ & $\mathbf{X}_{1}$ & $\mathbf{X}_{\mathbf{2}}$ & $\mathbf{X}_{\mathbf{3}}$ \\
\hline $\begin{array}{l}\mathbf{Y}_{\mathbf{6}} \\
\mathbf{Y}_{\mathbf{8}} \\
\mathbf{Y}_{2}\end{array}$ & $\begin{array}{r}+0.017 \\
+0.135 \\
+0.379\end{array}$ & $\begin{array}{r}+0.023 \\
-0.111 \\
-1.447\end{array}$ & $\begin{array}{l}+0.016 \\
+0.200 \\
+0.906\end{array}$ & $\begin{array}{r}+0.015 \\
+0.119 \\
+0.359\end{array}$ & $\begin{array}{r}+0.022 \\
-0.120 \\
-1.462\end{array}$ & $\begin{array}{l}+0.016 \\
+0.218 \\
+0.863\end{array}$ \\
\hline
\end{tabular}

comparison within and between social classes byô analysis of covariance. For stature there was no difference among the regression coefficients in the five socio-economic classes, but the differences between class means, after adjustment for the? regression on the other variables, just failed to reach significance $(0.10>P>0.05)$. This suggests that the socio-economic effect detected by arranging the classes in numerical sequence does not lie in any difference in response to the independent variables, but in the level at which that response occurs; if classes 1 and 2 are combined these levels are prof gressively higher the better the social class (Table I) In the regressions for ponderal index and for weighto there were no significant differences, either among the five adjusted social class means or among the 
regression coefficients. Since the results of this covariance analysis confirm those of the simpler multiple regression (and, indeed, the regressions within social class are very similar to the overall) no further covariance analysis was undertaken.

Of the zero order correlation coefficients between the independent variables, that between position in family and size of family ( +0.686$)$ was, of course, expected, but there was also a significant negative correlation $(r=-0.081)$ between size of family and year of birth, and a highly significant correlation between social class and year of birth $(\mathrm{r}=-0.128)$; it seems that girls from the lower social classes tend to be slightly older at the time of entry to college than those from the higher.

There is a further source of variation to be considered before these results are accepted. The occurrence of regional variations in physique in Britain has been recognized since the pioneer investigations of Beddoe (1870), there being gradients of increasing stature and weight as one travels south-east across Wales and England (Roberts, 1953). The subjects in the present sample were classified according to county of origin, and Table IV sets out the physique variables for each county from which eight or more subjects were drawn. Six of the seven Welsh counties (including Monmouthshire) have mean heights below 63.9 in., the mean for the whole sample. In nine of the 12 English counties the mean heights exceed this figure, whereas Pembrokeshire is the only county in Wales to do so. Similarly, five of the seven Welsh counties are below the mean weight for the total, by contrast with only three out of 12 of the English. The gradients of weight and stature still appear to be detectable in the present series. Now University College, Swansea, was expanding in the years covered by the present intakes of girls, and there was a steady increase in the proportion of English girls admitted, from 32 per cent. in 1959, 35 per cent. in 1961, to 56 per cent. in 1964. To exclude the possible effects of such a change in composition of the sample, the multiple regression analysis was repeated on the 359 Welsh girls only (i.e., those from Wales, including Monmouthshire). The results are shown in Table V. Again, the regression equations of ponderal index and weight on the four variables are not significant, though a significant negative regression coefficient of weight on family size appears. But in the regression of height on the four variables, the effect of social class remains, there is a positive effect of position in family, a suggestion of a negative effect of family size and, most striking, the effect of year of birth is no longer significant, though the regression coefficient remains positive and, indeed, is only diminished by about 20 per cent. Obviously the apparent secular trend in height observed in the total sample derives from the increased numbers

TABLE IV

PHYSIQUE BY COUNTY

\begin{tabular}{|c|c|c|c|c|c|c|c|}
\hline County & No. in Sample & Mean & S.D. & Mean & S.D. & $\underset{\text { Mea }}{\mathbf{P}}$ & S.D \\
\hline $\begin{array}{l}\text { Caernarvonshire } \\
\text { Cardiganshire } \\
\text { Carmarthenshire } \\
\text { Cheshire } \\
\text { Denbigh } \\
\text { Essex } \\
\text { Glamorgan } \\
\text { Gloucestershire } \\
\text { Hampshire } \\
\text { Kent } \\
\text { Lancashire } \\
\text { London } \\
\text { Monmouthshire } \\
\text { Pembrokeshire } \\
\text { Stafordshire } \\
\text { Surrey } \\
\text { Warwickshire } \\
\text { Wilthire } \\
\text { Yorkshire }\end{array}$ & $\begin{array}{r}8 \\
9 \\
35 \\
18 \\
11 \\
11 \\
221 \\
28 \\
12 \\
17 \\
19 \\
38 \\
53 \\
9 \\
16 \\
8 \\
16 \\
8 \\
17\end{array}$ & $\begin{array}{l}63 \cdot 7 \\
63 \cdot 0 \\
62 \cdot 9 \\
64 \cdot 6 \\
63 \cdot 2 \\
65 \cdot 0 \\
63 \cdot 5 \\
64 \cdot 1 \\
64 \cdot 3 \\
64 \cdot 1 \\
63 \cdot 7 \\
64 \cdot 5 \\
63 \cdot 7 \\
64 \cdot 4 \\
63 \cdot 4 \\
65 \cdot 0 \\
65 \cdot 2 \\
65 \cdot 4 \\
63 \cdot 6\end{array}$ & $\begin{array}{l}2 \cdot 3 \\
1 \cdot 6 \\
2 \cdot 6 \\
2 \cdot 1 \\
1 \cdot 8 \\
2 \cdot 2 \\
4 \cdot 4 \\
2 \cdot 2 \\
3 \cdot 1 \\
2 \cdot 7 \\
2 \cdot 1 \\
2 \cdot 2 \\
2 \cdot 4 \\
3 \cdot 0 \\
2 \cdot 4 \\
2 \cdot 1 \\
2 \cdot 3 \\
1 \cdot 3 \\
2 \cdot 6\end{array}$ & $\begin{array}{l}118 \cdot 6 \\
121 \cdot 0 \\
130 \cdot 8 \\
129 \cdot 6 \\
131 \cdot 1 \\
133 \cdot 7 \\
126 \cdot 7 \\
126 \cdot 7 \\
133 \cdot 7 \\
128 \cdot 2 \\
127 \cdot 3 \\
129 \cdot 5 \\
126 \cdot 8 \\
126 \cdot 7 \\
128 \cdot 3 \\
130 \cdot 1 \\
129 \cdot 2 \\
133.5 \\
127 \cdot 4\end{array}$ & $\begin{array}{l}11 \cdot 5 \\
11 \cdot 3 \\
19 \cdot 2 \\
16 \cdot 1 \\
30 \cdot 6 \\
14 \cdot 1 \\
17 \cdot 3 \\
15 \cdot 1 \\
24 \cdot 9 \\
11 \cdot 1 \\
17 \cdot 0 \\
17 \cdot 9 \\
17 \cdot 1 \\
18 \cdot 3 \\
18 \cdot 3 \\
23 \cdot 1 \\
17 \cdot 8 \\
7 \cdot 7 \\
18 \cdot 2\end{array}$ & $\begin{array}{l}13 \cdot 0 \\
12 \cdot 8 \\
12 \cdot 4 \\
12 \cdot 8 \\
12 \cdot 5 \\
12 \cdot 7 \\
12 \cdot 7 \\
12 \cdot 8 \\
12 \cdot 6 \\
12 \cdot 7 \\
12 \cdot 7 \\
12 \cdot 8 \\
12 \cdot 7 \\
12 \cdot 9 \\
12 \cdot 6 \\
12.9 \\
12.9 \\
12 \cdot 8 \\
12.7\end{array}$ & $\begin{array}{l}0.3 \\
0.3 \\
0.5 \\
0.5 \\
0.7 \\
0.4 \\
0.5 \\
0.4 \\
0.3 \\
0.5 \\
0.5 \\
0.6 \\
0.5 \\
0.4 \\
0.5 \\
0.7 \\
0.5 \\
0.3 \\
0.6\end{array}$ \\
\hline
\end{tabular}

TABLE V

MULTIPLE REGRESSION ANALYSIS-WELSH GIRLS ONLY

\begin{tabular}{|c|c|c|c|c|}
\hline Regression Equations & \multicolumn{4}{|c|}{ Standard Errors of Regression Coefficients } \\
\hline $\begin{array}{l}Y_{b}=12.58+0.004 X_{1}+0.027 X_{2}+0.019 X_{2}-0.041 X_{4} \\
Y_{0}=59.75+0.095 X_{1}-0.225 X_{2}+0.399 X_{2}-0.209 X_{c} \\
Y_{1}=99.76+0.613 X_{1}-2.300 X_{2}+1.875 X_{2}+0.241 X_{4}\end{array}$ & $\begin{array}{l}0.015 \\
0.064 \\
0.507\end{array}$ & $\begin{array}{l}0.030 \\
0.128 t \\
1.019\end{array}$ & $\begin{array}{l}0.042 \\
0.177^{\circ} \\
1.412\end{array}$ & $\begin{array}{l}0.024 \\
0.104 \\
0.828\end{array}$ \\
\hline
\end{tabular}

-Significance of $t$ ratio $P<0.05$

+Significance of $t$ ratio $0.10>P>0.05$ 
of English girls included. Again, however, the multiple correlation coefficient $R$ is not high, the values in the Welsh series for ponderal index, weight, and height being $0.128,0.144$, and 0.184 respectively.

As regards physique, then, ponderal index seems not to be affected by family environment in the present total sample, and weight only by family size in the Welsh subsample. But it appears that the height of the girl is, indeed, affected, height varying with the socio-economic class of the father and, in the Welsh subsample, with position in family and, perhaps, family size; that is to say, there are discernible effects both of class and of family environment on height. The apparent secular trend in height in the total sample seems to be due largely to a change in composition of the sample.

\section{Discussion}

These findings for stature are rather different from those of the earlier analysis of menarcheal age in the same sample. As regards maturation, the data showed a significant secular trend to diminishing menarcheal age; girls in larger families tended to be delayed in their menarche; girls born later in families of a given size tended to mature earlier; there was no association with socio-economic status, whether this was analysed by regression, taking class as a numerical variable, or by covariance without making any such assumption. A first analysis of physique in the same sample also seemed, apparently, to demonstrate a secular trend to increasing stature, no effect of family size or position on height, but a clear effect of social class. Some explanation of the apparent discrepancy is provided by elimination of gross geographical variations in physique and analysis of the more homogeneous Welsh series. Here are observed effects of family size and position, previously obscured by the additional variability in the total sample; the first diminishes, the second increases height in the Welsh series and they are thus similar to their effects on menarcheal age, which they respectively retard and accelerate. But the apparent secular trend in height overall is no longer significant in the Welsh series (i.e., when the effect of regional stature differences is eliminated), although the secular trend in menarcheal age still occurs. Then there still remains the curious contrast as regards social class; its effect on stature is shown both in the total series and in the Welsh subsample, whereas its effect on menarcheal age is absent in both. The question that prompted this analysis has thus been answered; clearly, socio-economic differences have not been eliminated as influences on the biological development of these girls.
To interpret this apparent contrast, it is necessaryo first to enquire whether the present findings are compatible with others reported in the literature, ando secondly to examine the explanations proposed. The demonstration of a social class effect on height is? in accordance with other studies which show? similar class differences in Britain (Hammond, 1957; Berry and Cowin, 1954; Tanner, 1965). The absence of a significant increase in height with yearo of birth, in the Welsh sample, may be attributed to the small range of birth years covered (less than $a-$ decade) and the small sample size, and, therefore; the present data are inadequate to show secular $\omega$ change; it is of relevance that the regression coefficient is in the same direction as the well-established secular trend that has occurred in western European young adult populations since about 1870 at thew rate of 0.6 to $0.8 \mathrm{~cm}$. per decade (Tanner, 1965). The effect of family size on stature in the Welsh sample,, though only on the borderline of significance, is in accordance with what is reported elsewhere. Scott's (1962) data on 10- and 11-year-old children showed a significant negative correlation of stature with $\log$ family size, and a decrement in boys of someco $0.6 \mathrm{~cm}$. and in girls of $0.7 \mathrm{~cm}$. per additional sib.6 Tanner (1962) notes that in Scott's (1961) data, In London, schoolboys aged 13 with no sibs averaged $2.7 \mathrm{~cm}$. greater than those with four or more sibs, and the corresponding figure for girls was $2.3 \mathrm{~cm}$ A similar decrement is apparent in 20-year-oldo French army recruits (Trémolières and Boulanger 1950) and a somewhat smaller one in 19-year-old? Norwegian conscripts (Udjus, 1964). In our data, the regression coefficient of stature on family size shows a decrement of $0.6 \mathrm{~cm}$. per sib, and so is comparable with the findings in these other surveys Again, the effect of position in family is in the same? direction as other reports. Grant (1964), studying the growth records of L.C.C. children, analysed the height differences between consecutive pairs of children and found the later child to be taller than its predecessor by about $0.8 \mathrm{~cm}$. This effect, moreover, was independent of family size with which $\frac{D}{0}$ again, height and weight at each birthday (6th, 10th, 12th, 14th) consistently declined. In our Welsh data the regression coefficient of height on position in family indicates an increase of approximately $1 \mathrm{~cm}$. per sib position, and is thus quite similar to Grant's figure.

The most convincing explanation of the effect of family size on stature observed in other studies? has been couched in simple environmental terms.0 the more mouths to feed and children to care for, thes? lower the standards of feeding and general care attained (Tanner, 1962); and in this respect feeding $\vec{D}$ 
in infancy, particularly as regards protein consumption, seems critical. Similar factors probably account for the effect of position in family; this was interpreted by Grant (1964) as indicating that the advent of each additional child per family acts as a check to the growth of all preceding sibs, and this interpretation was supported by the evidence of birth spacing, children following soon after their older sib tending to be smaller than those where there is a greater interval; environment, either in infancy or antenatally, seems clearly implicated. The social class effect appears more complex in origin; it is by no means clear to some that 'class' is anything other than an indirect measure of some more fundamental variable, such as nutrition, or the standard of parental care given to the child (Berry and Cowin, 1954). All these variables of home environment are closely interrelated; with better socio-economic status generally occur better nutrition, the habits of regular meals, sleep, exercise and general organization, so that no study has yet been able to disentangle their effects. Where this has been partly attempted (Bransby, Burn, Magee, and MacKecknie, 1946; Abramson and Ernest, 1954) it is found that growth differences are more closely related to the home conditions than to the strictly economic status of the family, home conditions reflecting the intelligence of the parents. From this type of consideration, Tanner (1965) cautions that class differences may not be entirely due to nutrition. He suggests that class differences are, perhaps, more characteristic of the sort of person who reaches a particular social class than of the circumstances in which, as a member of that class, he lives. Cliquet's (1967) demonstration that the biological characters of a socially mobile individual are more similar to those of the class to which he aspires than to those of the class from which he originates, is further evidence for this explanation. Similarly, though the secular effect on stature has been partly attributed to nutrition and improved living conditions, a good case has also been made out for some genetic trend, a breakdown of isolates over the last century and a half leading to increased heterozygosis and consequent heterosis.

Thus, of the four independent variables considered in this study, the effects are, in direction and magnitude, comparable with those elsewhere reported for samples for Britain with the exception of the secular trend which the present data are inadequate to show. As regards the explanations of their effects that have been advanced, there appears to be a distinction between two (family size and position in family) which reflect the immediate environment and two (birth year and social class) whose effects are of more complex determination. Our findings show the similarity of the effects of the former pair on both stature and menarcheal age-respectively, diminution and retardation, or increase and acceleration. An environmental explanation appears reasonable, though the results seem to indicate some factor other than nutrition in infancy. It has been pointed out that the early years of the subjects' lives were a period of nutritional uniformity. In particular, the amount of protein available for consumption was among the most rigidly controlled components of the diet in the early days of the girls' lives. If this were solely responsible, the variables of family size and family position would not exert a detectable effect on stature. But probably the protein intake of each was not equal; the system of rationing (so much cash value per head) was such that some families could be more efficient in the use of the rations available to them or more knowledgeable in the choice of foods they bought than others, so there was still room for some variation. Variation in antenatal environment as well as nutritional variation later in life may well have been of importance.

But it is the latter pair of variables that poses problems. Sampling may well account for the different findings for the effect of year of birth on menarcheal age and stature; this the continuation of the present study will show. But the differences in effect of social class are not so easily dismissed. Certainly, the explanation as to why stature, but not menarcheal age, in Britain shows a social class effect does not seem to lie in factors of the immediate environment, since the data on stature and maturation were from the same individuals. Perhaps, then, it should be sought in genetic factors.

Tanner (1966) has argued that the social class gradient in height in Britain represents a dynamic equilibrium, a steady-state process that arises from taller individuals tending to move up, and shorter individuals to move down the social scale. This social selection, since much of the variability in stature is genetic, results in genetic selection, a greater frequency of genes promoting taller stature in the upper classes and smaller stature in the lower. Although there is evidence that both stature and menarcheal age are to a large extent under multifactorial genetic control, there is reason to suppose that the same genes do not act on both, though there is little evidence on this point (Tanner, 1962, page 117); certainly, no phenotypic correlation appears, though this is not conclusive. Hence, the upward class migration of genes for tallness would carry with it a random sample of menarcheal age genes, so no social class gradient on menarcheal age would appear. Should there be any pleiotropism, however, 
then, since body size and age at initiation of reproduction are likely to be among the many components of genetic fitness, any genetic correlation between these characters may well be negativeparticularly if they are major components of fitness -and, again, selection for stature will not have a parallel effect on maturation. Thus, the contrast between the associations of social class with stature and with menarcheal age may well be explicable on the basis of their genetic determination. This is, of course, only a hypothesis, but it shows the direction in which investigations could profitably be pursued and the type of information at present lacking.

The interpretation of the results needs to recognize possible bias due to sampling. It may be that the families of the girls of, say, classes 1 or 4 who attained entry into university are not characteristic of the totality of families of classes 1 or 4 , and that the sample is unrepresentative. This possibility cannot be discounted, but if such a bias exists it will tend to reduce any real differences; these will, in fact, be more pronounced than those observed, but the environmental interpretation of the family size and position effects will remain valid. Of the findings for weight and ponderal index, the only comment necessary is that some proportion of the residual variance for both these variables derives from the sensitivity of weight to variations in the immediate environment, and any underlying relationships that may exist are thereby obscured.

\section{SUMmary AND CONCLUSIONS}

The physique of 655 girls born in 1939-1946, who entered University College, Swansea, in the period 1959-1964, was investigated to see whether variations in height, weight, and ponderal index were correlated with various factors in their family environment. Analysis was by multiple regression. Ponderal index is not affected by any of the variables, but stature shows correlations with family environment and socio-economic class. An apparent secular trend to increasing stature is due to the presence of an increasing proportion of girls from England who tend to be taller. Family size tends to diminish height, position in family increases height; the effects of these two factors on stature are thus similar to their effects on menarcheal age previously demonstrated in this sample, suggesting an environmental mechanism. Socio-economic class of the father influences stature, though in contrast it has no effect on menarcheal age. The effects of the variables of family environment on stature are in direction and magnitude comparable with those elsewhere reported for British samples. The cause of the contrast in the effect of social class on stature and menarcheal age, it is suggested, perhaps lies in genetic factors.

Acknowledgement is gratefully made to $\mathrm{Mr}$ J. Clowes of the Newcastle University Computing Laboratory for his considerable assistance with the programming and analysis; to Mrs. Marjorie Smith for her patient computational work; to $\mathrm{Mr}$ J. C. Smith and the staff at A.D.P. Branch, Ministry of Social Security, Newcastle upon Tyne, who eased the burden of data preparation. To Dr W. A. Marshall special thanks are expressed for his valuable comments and criticisms.

\section{REFERENCES}

Abramson, E., and ERNEST, E. (1954). Height and weight of schoolboys at a Stockholm secondary school, 1950, and a comparison with some earlier investigations. Acta. paediat. (Uppsala), 43, 235.

BEDDOE, J. (1870). On the stature and bulk of man in the British Isles. Mem. anthrop. Soc. Lond., 1867-8-9, 3, 384.

Berry, W. T. C., and Cowin, P. J. (1954). Conditions associated with the growth of boys, 1950-1. Brit. med.J., $1,847$.

BRANSBY, E. R., BURN, J. L., MAGeE, H. E., and MACKECKNIE, D. M. (1946). Effect of certain social conditions on the health of schoolchildren. Ibid., 2, 767.

Clements, E. M. B., and Pickett, K. G. (1957). Stature and weight of men from England and Wales in 1941? Brit. J. prev. soc. med., 11, 51.

Cliquet, R. L. (1967). Social Mobility and Anthropological Structure of a Population. Inst. voor Dierkunde, Ghent.

Dovglas, J. W. B. (1964). The Home and the School. MacGibbon and Kee, London.

GRANT, M. W. (1964). Rate of growth in relation to birth rank and family size. Brit. J. prev. soc. Med., $18,35$.

HAMMOND, W. H. (1957). Some aspects of growth with norms from birth to 18 years. Ibid., 11, 131 .

NisBet, J. D., and IllesLeY, R. (1963). The influences of early puberty on test performance at age 11 . Brit. $J$. educ. Psychol., 33, 169.

ROBERTS, D. F. (1953). Body weight, race and climate. Amer. J. phys. Anthrop. 11, 533.

$\longrightarrow$, and DANN, T. C. (1967). Influences on menarcheal age in girls in a Welsh college. Brit. J. prev. soc. Med., 21, 170.

ScoTT, J. A. (1961). Report on the Heights and Weights (and other measurements) of School Pupils in the County of London in 1959. County Council, London.

(1962). Intelligence, physique, and family size. Brit. J. prev. soc. Med., 16, 165.

TANNER, J. M. (1962). Growth at Adolescence. 2nd ed., Blackwell, Oxford.

(1965). The trend towards earlier physical maturation. In Biological Aspects of Social Problems. p. 40. ed. Meade, J. E., and Parkes, A. S. Oliver and Boyd, London. 
(1966). Galtonian eugenics and the study of growth. Eugen. Rev., 58, 122.

Thomson, A. M. (1959). Maternal stature and reproductive efficiency. Ibid., 51, 157.

Trémolières, J., and Boulanger, J. J. (1950). Contribu- tion à l'étude du phénomène de croissance et de stature en France de 1940 à 1948. Rec. Trav. Inst. nat. Hyg. (Paris), 4, 117.

UDJUs, L. G. (1964). Anthropometrical Changes in Norwegian Men in the Twentieth Century. Universitetsforlaget, Oslo. 